\title{
RETRACTED ARTICLE: COMPARATIVE STUDY OF QUALIFICATION AND ORGANIZATIONAL COMMITMENT AMONG THE FACULTY OF PRIVATE UNIVERSITIES
}

YASIR KHAN, SAIMA BATOOL

\author{
Abstract: \\ Retracted Article \\ Keywords: \\ Retracted Article \\ Authors: \\ YASIR KHAN, Qurtuba University Peshawa, Pakistan, Email: yasirok62@yahoo.com \\ SAIMA BATOOL, Qurtuba University Peshawar, Pakistan, Email: dr.saimabatool90@yahoo.com
}

\section{Citation:}

YASIR KHAN, SAIMA BATOOL (2017). Retracted Article: COMPARATIVE STUDY OF QUALIFICATION AND ORGANIZATIONAL COMMITMENT AMONG THE FACULTY OF PRIVATE UNIVERSITIES. International Journal of Business and Management, Vol. V(1), pp. 51-61., 10.20472/BM.2017.5.1.004 
The article was retracted for author's unethical behavior - the same article has been published in another journal. 
The article was retracted for author's unethical behavior - the same article has been published in another journal. 
The article was retracted for author's unethical behavior - the same article has been published in another journal. 
The article was retracted for author's unethical behavior - the same article has been published in another journal. 
The article was retracted for author's unethical behavior - the same article has been published in another journal. 